A C G

Rec. Nat. Prod. 12:6 (2018) 611-618

records of natural

publications

products

\title{
Alkaloids of Papaver libanoticum and their Cytotoxic Activity
}

\author{
Mohamad Ali Hijazi $\odot^{1 *}$, Maha Aboul-Ela ${ }^{1}$, Kamal Bouhadir ${ }^{2}$, \\ Maamoun Fatfat $\odot^{3}$, Hala Gali-Muhtasib $\odot^{3,4}$ and Abdalla Ellakany $\odot^{1}$
}

\author{
${ }^{1}$ Department of Pharmaceutical Sciences, Beirut Arab University, Beirut, Lebanon \\ ${ }^{2}$ Department of Chemistry, American University of Beirut, Beirut, Lebanon \\ ${ }^{3}$ Center for Drug Discovery, Faculty of Medicine, American University of Beirut, Beirut, Lebanon \\ ${ }^{4}$ Department of Biology, American University of Beirut, Beirut, Lebanon
}

(Received November 24, 2017; Revised February 06, 2018; Accepted February 08, 2018)

\begin{abstract}
Papaver libanoticum (family Papaveraceae) is an endemic Lebanese plant that has not been investigated before. The plant extract was found to possess a potent opioid analgesic activity with characteristic profile that suggest its potential use for the treatment of opioid abuse and withdrawal symptoms. The present study aims at exploring the cytotoxic activities of the plant extract and the isolated alkaloidal compounds. Chromatographic separation of Papaver libanoticum extract resulted in the isolation of; dehydroremerine (1), roemerine (2), berberine (3), alborine (4), remrefidine (5), and mecambrine (6). Their chemical structures were determined based on different recorded spectroscopic data in addition to comparison with those published in literature. The cytotoxic activity of the plant extract and its alkaloids (2-5) were determined by MTT assay on human breast cancer (MCF7) and human colon cancer cells (HCT116). The results indicated that berberine exhibited the highest inhibitory effect against both cell lines with $\mathrm{IC}_{50}$ of 22 and $106 \mu \mathrm{M}$ on MCF7 and HCT116 cells, respectively. Other compounds (including the crude extract) showed different dose-dependent inhibitory effects on the two cell lines indicating cell type specificity and suggesting different cell-alkaloid interactions. Further studies are needed to explore the structure-activity relationships (SAR) of alkaloids derived from $P$. libanoticum.
\end{abstract}

Keywords: Cytotoxic activity; Papaver libanoticum; aporphine alkaloids; spectroscopic analysis. @ 2018 ACG Publications. All rights reserved.

\section{Introduction}

Plants of family Papaveraceae are very important medicinally as they synthesize many pharmacologically active alkaloids [1]. Plants of the genus Papaver synthesize a wide range of therapeutically active and complex structured alkaloids. Many of these alkaloids have anticarcinogenic, antioxidant, anti-mutagenic [2-4], antimicrobial and anti-inflammatory activities [5].

\footnotetext{
*Corresponding author: E-Mail: m.hijazi@bau.edu.lb; Phone:009611--300110 Ext:2794
} 
Papaver libanoticum is an endemic plant to Lebanon [6]. It is a small herb with yellow-orange latex, oblong leaves, covered with white silky hairs. The petals are orange-red, capsule is black-blue with four stigmas [6]. It grows widely at higher altitudes in Lebanon like Makmel, Cedars,and Sannine Mountains.

Our interest in Papaver libanoticum has extensively increased especially after it was shown to have potent analgesic compounds that act via the activation of opioid receptors in the central nervous system [7]. This activity, which was characterized by slow onset and prolonged duration, suggested Papaver libanoticum extract (PLE) as a potential medication for the treatment of opioid abuse and withdrawal symptoms. The analgesic activity of PLE could be attributed to its alkaloids content [7].

Accordingly, the present paper aimed to explore the main alkaloids of Papaver libanoticum growing in Lebanon through combined spectral data analysis and characterization. Additionally, the cytotoxic activity of the total PLE and the isolated compounds was performed against HCT116 human colon cancer cells and MCF7 human breast cancer cells.

\section{Materials and Methods}

\subsection{General}

NMR spectra $\left({ }^{1} \mathrm{H}-\right.$ and ${ }^{13} \mathrm{C}-\mathrm{NMR}$, DEPT, COSY, NOSY, HCCOSW, and HMBC) were measured on a Bruker Ascend ${ }^{\mathrm{TM}} 500$ spectrometer fitted with Avance III HD, using deuterated solvents $\mathrm{CDCl}_{3}$. Mass spectra were recorded on an Agilent LC/MSD Trap XCT mass spectrometer. The ions were generated by ESI (Electrospray Ionization), and the system was controlled by the LC/MSD ChemStation software (version A.09.03). Agilent 1100 series HPLC equipped with quaternary pump G1311A, diode array detector G1329A was used for separation using BDS-HYPERSIL C18 ERSIL (5 $\mu \mathrm{m} ; 250 \times 4.6 \mathrm{~mm}^{2}$ ) with mobile phase flow rate of $1 \mathrm{~mL} / \mathrm{min}$. The mobile phase consisted of (Solvent A, $\mathrm{H}_{2} \mathrm{O}$; Solvent $\left.\mathrm{B}, \mathrm{MeOH} ; 1: 1\right)$. The sample injection volume was $20 \mu$ l. Melting points $(\mathrm{mp})$ were measured by a DigiMelt MPA 161 digital apparatus.

\subsection{Plant Material}

Aerial parts of Papaver libanoticum were collected, during the flowering period in May 2015, from Mount Lebanon Cedars, Arze Chouf, Arze Barouk (2000-2500 m above sea level). The plant was authenticated by Dr. George Tohme, Professor of Taxonomy (National Council for Scientific Research (CNRS), Beirut, Lebanon). A voucher specimen (pl-17-15) was deposited in the herbarium of the Faculty of Pharmacy, Beirut Arab University, Beirut, Lebanon. The plant was dried under shade at room temperature, and the dried aerial parts were ground into moderately coarse powder.

\subsection{Preparation of Plant Extract}

The dried plant powder $(12 \mathrm{~kg})$ were extracted extensively with four successive portions of ethanol $96 \%(4 \times 30 \mathrm{~L})$ at room temperature. The alcoholic extract was concentrated under reduced pressure at $42-45^{\circ} \mathrm{C}$ to get the crude powder.

\subsection{Extraction of Alkaloids}

The crude powder was extracted with $10 \%$ sulphuric acid $(500 \times 6 \mathrm{~mL})$, then washed with diethyl ether $(400 \times 2 \mathrm{~mL})$ and the washings were discarded. Concentrated ammonium hydroxide $\left(\mathrm{NH}_{4} \mathrm{OH}\right)$ was added to the aqueous extract to render it alkali $(\mathrm{pH}=9)$, then extracted with methylene chloride $\left(\mathrm{CH}_{2} \mathrm{Cl}_{2}, 12\right.$ x $\left.500 \mathrm{~mL}\right)$ and subsequently with methylene chloride: methanol (9:1) until no further alkaloid was detected [8]. Finally, the combined organic extracts were rinsed with water $(500 \mathrm{~mL})$, dried over anhydrous $\mathrm{Na}_{2} \mathrm{SO}_{4}$, then concentrated again under reduced pressure to yield $18 \mathrm{~g}$ of total $P$. libanoticum alkaloids $(0.15 \%$ yield). 


\subsection{Chromatographic Isolation of Compounds}

$10 \mathrm{~g}$ of the alkaloids were separated by column chromatography (CC) using neutral alumina $(1000 \mathrm{~g}$, column diameter $5 \mathrm{~cm})$. Gradient elution was applied using mixtures of petroleum ether and ethyl acetate (PE: EtOAc, 30 to 100\% EtOAc) and then EtOAc and methanol (EtOAc: $\mathrm{MeOH}, 0$ to $100 \% \mathrm{MeOH})$ to give 50 fractions $\left(\mathrm{A}_{1}-\mathrm{A}_{50}\right)$ each $250 \mathrm{~mL}$. Each fraction was spotted on TLC using suitable mobile solvents, detected by UV lamp, and visualized by spraying with dragendorff's reagent. Based on TLC analysis $\left(\mathrm{R}_{\mathrm{f}}\right.$, shape, and color of spot), similar fractions were combined together for further purification through CC, preparative TLC (PTLC, Silica-gel GF254, 20 x $20 \mathrm{~cm}, 0.5 \mathrm{~mm}$ thickness), and crystallization to get single pure crystalline compounds. Accordingly, fractions $\mathrm{A}_{3}$ and $\mathrm{A}_{4}$ showed spot of an alkaloid that reacted with Dragendorff's reagent to give orange color. These two fractions were gathered and subjected to PTLC. Elution was carried out with mixtures of petroleum ether and ethyl acetate (PE: EtOAc, 70:30) to give alkaloid 1. Similarly, three alkaloids appeared in the fractions $A_{5}, A_{6}$, and $A_{7}$ with same retention factor $\left(R_{f}\right)$. These fractions were also combined together, subjected to PTLC, and developed by mixtures of $\left(\mathrm{CHCl}_{3}: \mathrm{MeOH}, 97: 3\right)$. Only major alkaloidal band was scratched and recrystallized from methanol to give the alkaloid 2 . Yellow bright crystals freely precipitated from fractions $A_{27}$ and $A_{28}$ to give compound 3. Fractions $A_{29}$ and $A_{30}$ showed two alkaloidal spots on TLC. They were gathered and subjected to PTLC developed by $\mathrm{CHCl}_{3}: \mathrm{MeOH}(85: 15)$ to give two alkaloidal bands. Band 2 (major) was scratched, extracted, and recrystallized from $\mathrm{MeOH}$ to give compound 4. Fraction $\mathrm{A}_{31}-\mathrm{A}_{36}$ were combined and passed over $\mathrm{CC}$ (silica gel $200 \mathrm{~g}, 3.5 \mathrm{~cm} \times 40 \mathrm{~cm}$ ), eluted with a gradient mixture of chloroform and methanol (from 5$30 \%$ ). The major alkaloidal fractions were detected by TLC, combined together, and then subjected to PTLC for further purification using mixture of $\mathrm{CHCl}_{3}: \mathrm{MeOH}(80: 20)$ to give alkaloid $\mathbf{5}$. Alkaloid $\mathbf{6}$ was isolated from fractions $\mathrm{A}_{37}-\mathrm{A}_{38}$ after purification by PTLC and recrystallization in $\mathrm{CHCl}_{3}$ : $\mathrm{MeOH}$ solution.

\subsection{Chemicals}

All organic solvents for CC and TLC (PE, EtOAc, and $\mathrm{MeOH}$ ) were analytical grade and obtained from Sigma-Aldrich ${ }^{\circledR}$ (Germany). The used alumina was Neutral alumina 507 (for CC), and silica gel Silica-gel $\mathrm{GF}_{254}$ (for preparative TLC) were obtained from Fluka ${ }^{\circledR}$ (Switzerland). TLC was performed on pre-coated silica gel $60 \mathrm{~F}_{254}$ obtained from ALUGRAM ${ }^{\circledR}$ SIL G (Germany). Methanol used for recrystallization, LC-MS, UV analysis was HPLC-grade purchased from Sigma-Aldrich ${ }^{\circledR}$ (Germany).

\subsection{Cell Culture and Treatment}

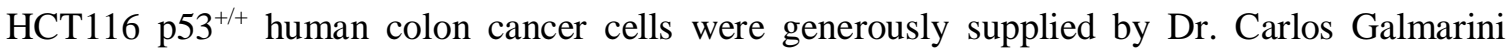
(Institut National de la Santé et de la Recherche Médicale, Lyon, France). ATCC supplied the human breast cancer cell lines MCF-7 (p53 wildtype, noninvasive). HCT116 p53 ${ }^{+/+}$and MCF-7 were cultured in RPMI 1640 (Sigma-Aldrich, UK) with $20 \mathrm{mM}$ HEPES and L-Glutamine. 1\% PenicillinStreptomycin $(100 \mathrm{U} / \mathrm{mL})$ and 10\% heat-inactivated FBS (Sigma-Aldrich, Germany) were then added to the media. Cells were kept in an incubator $5 \% \mathrm{CO}_{2}$ and $95 \%$ air at $37^{\circ} \mathrm{C}$. Cells were seeded at 1.2 x $10^{5}$ cells $/ \mathrm{mL}$, and were then treated at $50 \%$ confluency with the isolated compounds $(\mathbf{2}, \mathbf{3}, \mathbf{4}$, and $\mathbf{5})$ and with the Doxorubicin (Sigma D-1515) as positive control. The final DMSO concentration used on cells was less than $0.3 \%$.

\subsection{Cell Viability Assays}

Cells were plated in 96-well plates and treated with roemerine, berberine, alborine, remrefidine, and the total ethanolic extract at different concentrations. 3-(4,5-dimethyl-2-thiazoyl)-2, 5-diphenyltetrazolium bromide (MTT) was used for the measurement of metabolic activity according to manufacturer's instructions (Abcam: ab146345). $0.5 \mathrm{mg} / \mathrm{mL}$ MTT was then added to each well followed by incubation for 4 hours. After that, we incubated the cells with lysis buffer overnight. The 
absorbance of soluble formazan was determined at $570 \mathrm{~nm}$ wavelength using a BioRad plate reader. The $\mathrm{IC}_{50}$ shown in Table 1 is the concentration at which $50 \%$ of the cells remain viable.

\subsection{Statistical Analysis}

Each experiment was performed at least in triplicate. Data are expressed as the mean \pm standard deviation, and statistical significance between different groups was determined using a two-tailed Student's t-test. Statistical significance was defined as a $* p<0.05$ and $* * p<0.01$.

\section{Results and Discussion}

\subsection{Structure Elucidation}

Alkaloid 1, 2, and 5 was isolated in the form of brown, colorless, and yellow crystals respectively. Their molecular formulas were concluded from combined analysis of spectroscopic data as $\mathrm{C}_{18} \mathrm{H}_{15} \mathrm{NO}_{2}, \mathrm{C}_{18} \mathrm{H}_{17} \mathrm{NO}_{2}$, and $\mathrm{C}_{19} \mathrm{H}_{20} \mathrm{NO}_{2}$ respectively. The characteristic proton signals of aporphine class were present in the three alkaloids [9]. Moreover, the non-substituted ring D was evident through the appearance of four interacting aromatic protons. The absence of methylene group at C-7 and methine group at C-6a suggested that alkaloid $\mathbf{1}$ is the dehydro form of alkaloid $\mathbf{2}$ with unsaturation between C-7 and C-6a, while alkaloid $\mathbf{5}$ (remrefidine) appeared to be the N-methyl isomer of alkaloid 2. Accordingly, the three alkaloids were identified as dehydroremerine (1), roemerine (2), and remrefidine (5), where all their data were in good agreements with data available in the literature [10, 11 , and 12].

Alkaloids, berberine (3) and alborine (4) were obtained as bright yellow crystals. The shape and color of the crystal, its physical properties, and spectral data $\left({ }^{1} \mathrm{H}-\mathrm{NMR}\right.$ and $\left.{ }^{13} \mathrm{C}-\mathrm{NMR}\right)$ of alkaloid 3 were identical to that of berberine isolated previously [8]. Extensive and combined analysis of spectroscopic data of compound 4 revealed the molecular formula of $\mathrm{C}_{22} \mathrm{H}_{22} \mathrm{NO}_{6}$ and the promorphinane alkaloid skeleton. The ${ }^{1} \mathrm{H}-\mathrm{NMR}$ spectrum indicated the presence of three $-\mathrm{OCH}_{3}$ groups correlated to $\mathrm{C}-1, \mathrm{C}-10$, and $\mathrm{C}-11$, respectively. According to all correlations (NOSY, COSY, and HMBC), the chemical structure of alkaloid $\mathbf{4}$ was confirmed to be alborine [13]. Alkaloid $\mathbf{6}$ was isolated in the form of yellow crystals. Spectroscopic data revealed the characteristic signals of aporphine alkaloid with the molecular formula of $\mathrm{C}_{18} \mathrm{H}_{17} \mathrm{NO}_{3}$. The UV spectrum indicated the existence of conjugated system [14]. The ${ }^{1} \mathrm{H}-\mathrm{NMR}$ showed doublet doublet signal of the vinyl protons $\alpha, \alpha^{\prime}, \beta$ and $\beta^{\prime}$. The ${ }^{13} \mathrm{C}-\mathrm{NMR}$ spectrum revealed a very significant carbonyl signal at $\delta 185.8$ assigned to $\mathrm{C}-8$ with characteristic proaporphine quarternary C-7a spirocarbon appeared at $\delta 46.1$. Accordingly, the structure of alkaloid is the dehydroaporphine alkaloid mecambrine (6) [15]. Chemical structures of the isolated compounds (1-6) are presented in Figure 1

Family Papaveraceae and Fumariaceae were classified under the order Papaverales where their species contain alkaloids and not glucosinolates. The presence of tetrahydroisoquinoline alkaloids is a characteristic feature of both families [16]. Their biosynthetic pathway arises from phenylalanine by condensation of dopamine with 3,4-dihydroxyphenylacetaldehyde. Despite the fact that many of the isolated alkaloids were known compounds, this is the first phytochemical investigation of Papaver libanoticum plant. Alkaloids of Papaver libanoticum isolated in this study belongs to aporphine, promorphinane, and protoberine type of alkaloids. Previous phytochemical investigation of Papaver rhoeas grown in Lebanon has revealed five alkaloids (sinactine, canadine, stylopine, berberine, and epiberberine) belonging to protoberine class of alkaloids [8], which is in agreement with biosynthetic pathways in the Papaveraceae plant. Literature search showed that Papaveraceae alkaloids can be further divided into different types according to their chemical skeleton as benzylisoquinolines, isoquinolines, aporphines, proaporphines morphinans, promorphinans, pavines and isopavines, protoberberines and retroprotoberberines, cularines, secoberbines, protopines, benzophenanthridines, secophthalideisoquinolines, phthalideisoquinolines, spirobenzylisoquinolines indenobenzazepines, and rhoeadines [17]. 
<smiles></smiles>

1<smiles>Cc1c2c(cc3c1N(C)CC3)OCO2</smiles>

2<smiles>[R]c1c2c(cc3c1-c1cc4c([R4])c([R4])c([R4])[n+](C)c4cc1CC3)OCO2</smiles>

$\begin{array}{llllll} & \mathbf{R}_{1} & \mathbf{R}_{2} & \mathbf{R}_{3} & \mathbf{R}_{\mathbf{4}} & \mathbf{R}_{\mathbf{5}} \\ \mathbf{3} & \mathrm{H} & \mathrm{H} & \mathrm{OCH}_{3} & \mathrm{OCH}_{3} & \mathrm{H} \\ \mathbf{4} & \mathrm{CH}_{2} \mathrm{OH} & \mathrm{OCH}_{3} & \mathrm{OCH}_{3} & \mathrm{OCH}_{3} & \mathrm{OCH}_{3}\end{array}$<smiles></smiles><smiles>C[C@@H]1CC2c3c(cc4c(c3C13C=CC(=O)C=C3)OCO4)CCN2C</smiles>

Figure 1. Chemical structures of alkaloids 1-6.

The importance of Lebanese Papaver species arises from the reported biological activity of its alkaloids. Roemerine was reported to have antimicrobial activity against Staphylococcus aureus [18] and Candida albicans [19]. It also showed significant antiplasmodial activities with a good selectivity index [20]. Alborine demonstrated a significant and selective dose-dependent activity against the replication of poliovirus type 1 [13]. Again, berberine was reported to have therapeutic effects on the diseases of the endocrine system, digestive system, circulation system, respiratory system, and other systems [21]. It enhances the bactericidal effect of antibiotics and inhibit MRSA biofilm formation by affecting phenol-sol. modulins (PSMs) aggregation into amyloid fibrils [22].

\subsection{Cytotoxic Activity}

The effect of crude extract on growth inhibition of the cancer cell lines HCT116 and MCF7 was determined by MTT assay. The results of the cytotoxic activity of PLE and that of the tested compounds (roemerine, berberine, alborine, and remrefidine) are summarized in figure 2. Almost all compounds showed dose-dependent inhibitory activity on the cancerous cell lines. The most effective was berberine, with $\mathrm{IC}_{50}$ of 22 and $106 \mu \mathrm{M}$ on HCT116 and MCF7 cells, respectively (Table 1). Interestingly the crude ethanolic extract of Papaver libanoticum revealed significantly greater cytotoxic activity than alborine and remrefidine (Table 1), suggesting promising cytotoxic potential especially against colon cancer cells. The activity of isolated compound (except roemerine) were higher against MCF7 cancer cells than HCT116 cells. In addition, the activity of the ethanolic extract and all the isolated compounds varied between the cell types indicating cell type specificity and suggesting different modes of interaction of chemicals with the cells. On the other hand, despite the variation of the chemical constituents of Lebanese Papaver libanoticum and Papaver rhoeas, their cytotoxic activities were close with $\mathrm{IC}_{50}$ of 178 and $>200 \mu \mathrm{M}$ for P. libanoticum, 160 and $>200 \mu \mathrm{M}$ for $P$. rhoeas on HCT116 and MCF7 cells, respectively [8]. 


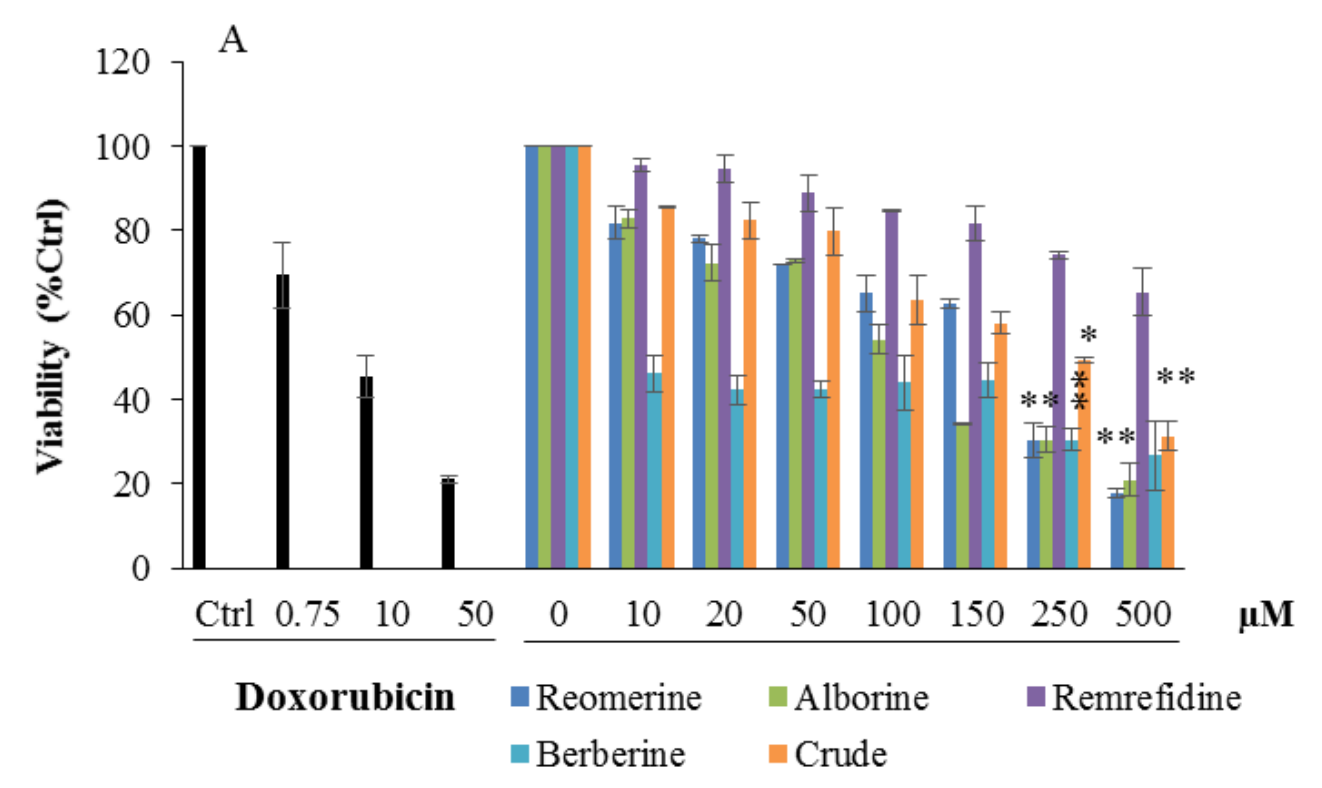

B

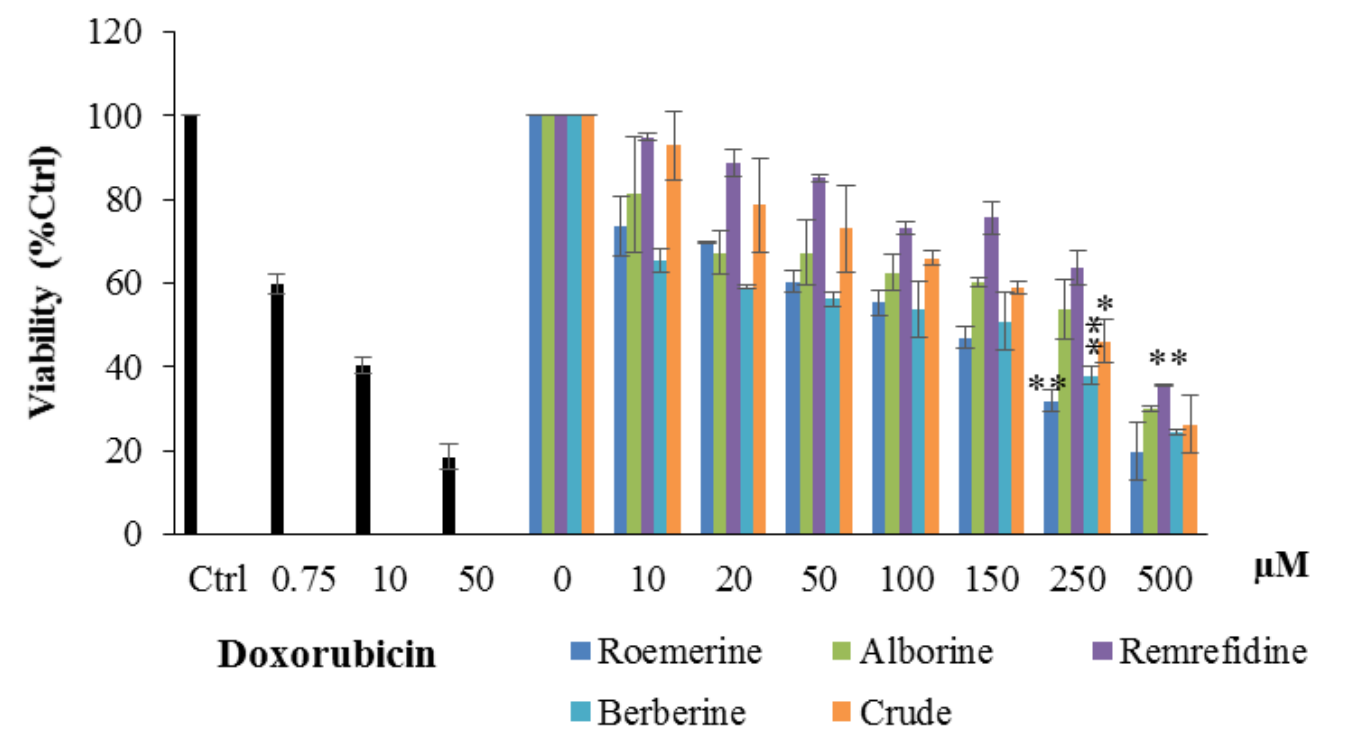

Figure 7. MCF7 (A) p53+/+ HCT116 (B), were treated at 50\% confluency with (roemerine, berberine, alborine, and remrefidine, and the total extract) $(0,10,20,50,100,150,250$, and $500 \mu \mathrm{M})$ for $24 \mathrm{~h}$. Cell viability was determined by the MTT assay. Results are expressed as percentage of non-treated cells. Each value is the mean $\pm \mathrm{SD}$ of three separate experiments each done in hexplicates. Results are expressed as percentage of non-treated cells. Each value is the mean $\pm \mathrm{SD}$ of three separate experiments each done in hexplicates for statistical analysis $* \mathrm{p}<0.05$ and $* * \mathrm{p}<0.001$, significant difference with respect to control.

Further extensive investigations or studies are needed to completely explore the relationship between the phytochemical properties of the plant, its ecological factors and subsequent biological activity. 
Table 1. $\mathrm{IC}_{50}$ of tested compounds and the total extract $(\mu \mathrm{M})$

\begin{tabular}{lll}
\hline Compound & $\begin{array}{l}\text { HCT116 } \\
\mathbf{I C}_{50} \pm \text { SD }(\boldsymbol{\mu M})\end{array}$ & $\begin{array}{l}\text { MCF7 } \\
\mathbf{I C}_{\mathbf{5} \mathbf{0}} \pm \text { SD }(\boldsymbol{\mu M})\end{array}$ \\
\hline Total extract & $178 \pm 2.9$ & $>200$ \\
Roemerine (2) & $141 \pm 2.9$ & $178 \pm 5.5$ \\
Berberine (3) & $106 \pm 5.9$ & $22 \pm 7.2$ \\
Alborine (4) & $>200$ & $192 \pm 6.4$ \\
Remrefidine (5) & $>200$ & $>200$ \\
\hline
\end{tabular}

\section{Conclusion}

This article represents the first report on the phytochemical investigation of the plant, showing that dehydroremerine, roemerine, berberine, alborine, remrefidine, and mecambrine represent its major alkaloidal content. Although Papaver libanoticum has potent analgesic activities and was suggested as a potential remedy for the treatment of opioid dependence and withdrawal symptoms [3], its cytotoxic activity was not exceptional. However, the cytotoxic activity of the alkaloids from Papaver libanoticum was comparable to those from Papaver rhoeas [8]. Further studies are recommended to track the analgesic activity of Papaver libanoticum whether related to its alkaloidal content or was due to other constituents to be discovered.

\section{Supporting Information}

Supporting information accompanies this paper on http://www.acgpubs.org/RNP

\section{ORCID}

Mohamad Ali Hijazi: 0000-0002-9829-235X

Maha Aboul-Ela: 0000-0002-9411-4900

Kamal Bouhadir: 0000-0002-6375-1763

Hala Gali-Muhtasib: 0000-0001-6840-3015

Maamoun Fatfat: 0000-0001-9642-6708

Abdalla Ellakany: 0000-0003-2122-2289

\section{References}

[1] H. Da Cheng, G. Xiao-Jie and G. X. Pei (2016). Phytochemical and biological research of Papaver pharmaceutical resources, Med Plants: Chem. Biol. 217-251.

[2] T. Todorova, M. Pesheva, F. Gregan and S. Chankova (2014). Antioxidant, antimutagenic, and anticarcinogenic effects of Papaver rhoeas L. extract on Saccharomyces cerevisiae, J. Med. Food 18, 460-467.

[3] S. Mazzini, M. C. Belluci and R. Mondelli (2003). Mode of binding of the cytotoxic alkaloid berberine with the Double Helix oligonucleotide D (AAGAATTCTT) 2, Bioorganic Med. Chem. 11, 505-514.

[4] K. Fukuda, Y. Hibiya, M. Mutoh, M. Koshiji, S. Akao and H. Fujiwara (1999). Inhibition by berberine of cyclooxygenase-2 transcriptional activity in human colon cancer cells, J. Ethnopharmacol. 66, 227233.

[5] Q. I. Hongyang, X. I. A. O. Zhanyu, M. A. Junbao, D. Shuangxia and W. Yunxi (2013). Comparative study of antimicrobial effects of three Chinese medicinal herbs containing protoberberine alkaloids. Lat. Am. J.Pharm. 32, 335-339. 
[6] G. Tohme and H. Tohme, "Illustrated flora of Lebanon," National Council for Scientific research, Beirut, Lebanon, 2014.

[7] M. A. Hijazi, A. El-Mallah, M. Aboul-Ela, and A. Ellakany (2017). Evaluation of analgesic activity of Papaver libanoticum extract in mice: involvement of opioids receptors, Evid. Based Complem. Alter. Med. 2017, 1-13.

[8] M. A. Hijazi, A. El-Mallah, M. Aboul-Ela, K. Bouhadir, M. Fatfat, H. Khalife, A. Ellakany, and H. Gali-Muhtasib (2017). Cytotoxic activity of alkaloids from Papaver rhoeas growing in Lebanon, Rec. Nat. Prod. 11, 211-216.

[9] J. Chen, K. Gao, T. Liu, H. Zhao, J. Wang, H. Wu, B. Liu and W. Wang (2013). Aporphine alkaloids: A Kind of alkaloids' extract source, chemical constitution and pharmacological actions in different botany, Asian J. Chem. 25, 10015-10027.

[10] T. T Thuy, T. V.Sung, K. Franke and L.Wessjohann (2005). Aporphine and proaporphine alkaloids from Stephania rotuda, J. Chem. 43, 619-623.

[11] C. Ma, J. Wang, H. Chu, X. Zhang, Z. Wang, H. Wang and G. Li (2014). Purification and characterization of aporphine alkaloids from leaves of Nelumbo nucifera gaertn and their effects on glucose consumption in 3T3-L1 adipocytes, Int. J. Mol. Sci. 15, 3481-3494.

[12] B. Kanyinda, R. Vanhaelen-Fastre and M. Vanhaelen, (1995). Benzylisoquinoline alkaloids from Anisocycla jollyana leaves, J. Nat. Prod. 58, 1587-1589.

[13] R. Istatkova, L. Nikolaeva-Glomb, A. Galabov, G. O. Yadamsuren, J. Samdan, S. Dangaa, and S. Philipov (2012). Chemical and antiviral study on alkaloids from Papaver pseudocanescens M. Pop., $Z$. Naturforch C. 67, 22-28.

[14] O. Hanita, M. H. Najihah, Z. Asdren, N. Noraziah, I. A. Siddiq, H. S. A. Ainnul, H. Abdel Hamid and M. A. Hapipah (2013). Aporphine alkaloids from the leaves of Phoebe grandis (Nees) Mer. (Lauraceae) and their cytotoxic and antibacterial activities, Molecules 18, 8994-9009.

[15] A. Sari, A. I. Gray and G. Sariyar (2004). A new dehydroaporphine alkaloid from Papaver fugax, Nat. Pro. Res. 18, 265-268.

[16] V. Preininger (1985). Chemotaxonomy of the Papaveraceae Alkaloids. In: J.D. Phillipson, M.F. Roberts and M.H. Zenk (eds) The Chemistry and Biology of Isoquinoline Alkaloids. Proceedings in Life Sciences. Springer, Berlin, Heidelberg

[17] P. Tétényi (1993). Chemotaxonomy of genus Papaver, Acta Hortic, 344, 154-165.

[18] S. Yin, G. Rao, J. Wang, L. Luo, G. He, C. Wang, C. Ma, X. Luo, Z. Hou and G. Xu (2015). Roemerine improves the survival rate of septicemic BALB/c mice by increasing the cell membrane permeability of Staphylococcus aureus, PLOS One, 10, 1-13.

[19] C. Ma, F. Du, L. Yan, G. He, J. He, C. Wang, G. Rao, Y. Jiang and X. Guili (2015). Potent activities of roemerine against Candida albicans and the underlying mechanisms, Molecules 20, 17913-17928.

[20] B. Baghdikian, V. Mahiou-Leddet, S. Bory, S. S. Bun, A, Dumetre, F. Mabrouki, S. Hutter, N. Azas and E. Ollivier (2013). New antiplasmodial alkaloids from Stephania rotunda, J. Ethnopharmacol. 145, 381-385.

[21] Z. Zou, Y. Wang, Y. Hu, S. Xia, D. Wang, J. Pang and X. Li (2014). Study of promoting effect of alkaloids from rhizoma coptidis on sleep of mice. Zhongg. Yaolixue Tongbao, 30, 1752-1756.

[22] M. Chu, M. Zhang, Y. Liu, J. Kang, Z. Chu, K. Yin, L. Ding, R. Ding, R. Xiao and Y. Yin (2016). Role of berberine in the treatment of methicillin-resistant Staphylococcus aureus infections. Sci. Rep., 6, 24748 .

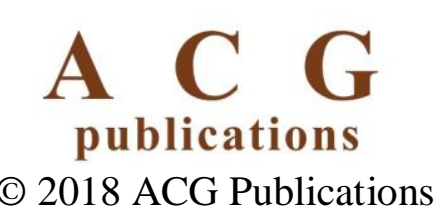

